\title{
RESSOAR A ANTROPOLOGIA: UMA JAM SESSION COM STEVEN FELD
}

\author{
Steven Feld ${ }^{1}$, Iracema Dulley², Evanthia Patsiaoura ${ }^{3}$, Maíra Vale $^{4}$, Catarina \\ Morawska ${ }^{5}$, Rafael do Nascimento Cesar $^{3}$ e Suzel Reily ${ }^{3}$ \\ ${ }^{1}$ School for Advanced Research, Estados Unidos \\ ${ }^{2}$ ICI Berlin Institute for Cultural Inquiry, Alemanha \\ ${ }^{3}$ Universidade Estadual de Campinas, Campinas, SP, Brasil \\ ${ }^{4}$ imuê - Instituto Mulheres e Economia, São Carlos, SP, Brasil \\ ${ }^{5}$ Universidade Federal de São Carlos, São Carlos, SP, Brasil
}

Steven Feld é pesquisador sênior da School for Advanced Research em Santa Fe e professor emérito de antropologia pela University of New Mexico. Sua monografia seminal Sound and Sentiment [Som e sentimento], de 1982, realizada a partir de anos de pesquisa na floresta Bosavi, na Papua Nova Guiné, é um marco etnográfico para a antropologia do som, da música e dos sentidos. Em 2012, lançou o livro Jazz Cosmopolitanism in Accra [O cosmopolitismo do jazz em Acra], juntamente com produções em CD e DVD de seu próprio selo, VoxLox, voltado para produções colaborativas. Seu distanciamento de abordagens clássicas em etnomusicologia aprofundou-se com pesquisas sobre jazz em Acra e a relação entre sinos, espaço e tempo na França, Finlândia, Noruega, Dinamarca, Grécia, Itália, Japão, Gana e Togo. Feld (2017) uniria, assim, "acústica" e "epistemologia" para cunhar o termo acustemologia, de modo a "compreender como a produção e a escuta do som (que inclui a música) podem ser um instrumento para a produção de conhecimento, de relações entre humanos e não humanos, e desses com o ambiente mais amplo" (Brito 2019). ${ }^{1}$ Suas experimentações com diversos modos de conhecimento por meio do imbricamento entre som, texto e imagem têm influenciado pesquisadores em antropologia, música e som, bem como linguistas, cineastas, fotógrafos e artistas das mais diversas áreas.

Entre os dias 4 e 6 de agosto de 2020, Feld participou do seminário virtual "Constituição de sujeitos em contextos africanos: diferenciações, iterações, interseccionalidades", promovido pelo Iterares: Laboratório de Estudos sobre Diferenciação e Interseccionalidade e associado ao projeto Fapesp homônimo desenvolvido na Universidade Federal 
de São Carlos. ${ }^{2}$ A conversa que aqui apresentamos ocorreu no dia 7 de agosto de 2020 e representa um desenvolvimento do diálogo entre Steven Feld e os pesquisadores do projeto durante o seminário. Assim como faz em suas jam sessions, Feld improvisou respostas para interpelações sobre temas tão variados quanto a constituição de sujeitos; teoria e narrativa na antropologia; antropologia e música; antropologia e política; antropologia linguística; a pandemia de coronavírus; produções colaborativas; engajamentos afetivos no trabalho de campo.

Para ressaltar um termo fundamental à sua perspectiva teórica, intitulamos originalmente a nossa interação Sounding Anthropology. A palavra sounding, na língua inglesa, evoca uma forma de pensar e perceber o som em duas dimensões simultâneas: acústica e temporal. ${ }^{3}$ Sound-ing implica, assim, um estado contínuo de produzir som, de estar em meio à ação ou ao processo de fazer soar. A escolha por "ressoar" na versão em português do título indica a relação sempre presente e dialógica entre soar e escutar na teoria do autor. Ressoar a antropologia, portanto, é um convite a perceber e a descrever os sons no tempo e no espaço onde eles soam, ecoam e ressoam.

Iracema Dulley: Começo com uma pergunta relacionada a nosso seminário. Steve, em sua conferência você colocou em questão os efeitos das palavras "diferenciação", "iteração" e "interseccionalidade" sobre a constituição de sujeitos: elas contribuiriam para determinar ou deslocar esses sujeitos? Gostei muito dessa formulação. A questão de como os sujeitos são constituídos e diferenciados aparece de forma bem marcada em sua etnografia, especialmente no livro Jazz Cosmopolitanism in Accra. Acho muito inspirador como a posicionalidade social relacionada à raça, classe, idade, educação, circulação cosmopolita e ao gênero se entrelaça à sua narrativa etnográfica. Você poderia falar mais sobre como seu trabalho confere tratamento etnográfico à discussão sobre constituição de sujeitos via som, texto e imagem?

Steven Feld: Nunca havia pensado sobre a formulação "constituição de sujeitos" até conhecer a forma como vocês a vêm usando em seu grupo de pesquisa. Subjetividade e intersubjetividade, no sentido da fenomenologia social de Alfred Schütz, são temas centrais para mim, mas a minha primeira oportunidade para pensar constituição de sujeitos foi com vocês. O que tentei fazer no projeto Jazz Cosmopolitanism foi deslocar biográfica, histórica e etnograficamente a noção de cosmopolitismo; mais especificamente, falar sobre cosmopolitismo a partir de baixo, ou seja, performatizar uma perspectiva antielitista do cosmopolitismo em diálogo com teóricos como Kwame Anthony Appiah, Pnina Werbner, James Clifford, Stuart Hall, Saskia Sassen e Hannah Arendt. Eu também queria pensar o projeto contemporâneo da antropologia como uma reteorização do cosmopolitismo: como os antropólogos reconfiguram a relação com a sua própria subjetividade e as subjetividades com as quais eles se engajam ao longo da pesquisa?

A constituição de sujeitos por meio do som foi um ponto de partida evidente para mim. Antes mesmo de ter qualquer conversa séria ou relação interpessoal com Nii Noi Nortey e Nii Otoo Annan, eu imediatamente ouvi, na forma como eles tocavam música, muitos aspectos familiares. ${ }^{4}$ Era como se ao andar e falar eles percorressem um caminho por mim já conhecido, em que eu poderia simplesmente pegar 
um instrumento, andar e conversar com eles. Essa intersubjetividade ocorre quando nos envolvemos profundamente em uma conversa com outros músicos, particularmente por meio da improvisação e da história dos idiomas musicais afrodiaspóricos do jazz e do blues. Logo na sequência, refleti muito sobre como Nii Noi e Nii Otoo criam um diálogo que às vezes é muito íntimo, muito tenso ou muito conflituoso, mas sempre muito enredado com o jazz norte-americano, o jazz mundial e os idiomas africanos.

Essa também foi uma forma de perguntar como, para Nii Noi e Nii Otoo, a constituição subjetiva no som constantemente se referenciava, mas também se distanciava; tornava-se próxima e familiar e, depois, diferente e distante. Como, então, a diferenciação no processo de constituição de sujeitos era explorada e realizada por meio da música africana e diaspórica? Para mim, a constituição de sujeitos refratava-se como relação entre práticas de escuta e práticas de musicar. ${ }^{5}$ Se eu estava escutando a história de escuta deles, sua história de escutar música africana e música afro-americana, qual era então a diferença? De que modo eu estava escutando a destilação de um processo histórico, o processo histórico pelo qual eles se tornaram diferentes de outros músicos e seus entornos, mas mantiveram múltiplos pontos de conversação? Minha primeira tentativa, assim, foi lidar com a subjetividade e a intersubjetividade naquele contexto africano por meio do som e da escuta, perguntando a mim mesmo: como pude viajar 10 mil quilômetros e sentir de forma tão instantânea que conheço Nii Noi e Nii Otoo há tanto tempo? Como posso pegar um instrumento e imediatamente estabelecer uma conversa íntima com eles, mas ao mesmo tempo perceber que essa conversa é diferente de qualquer outra que eu tenha estabelecido até então?

Subjetividade e constituição de sujeitos eram constantemente retrabalhadas para mim, como um espaço de agência, orgulho racial, orgulho de pertencer a um lugar, orgulho de ter uma habilidade por parte de atores coetâneos que nunca se fixaram em uma localidade distante chamada "tradição africana". Essa maneira de fazer soar e escutar expressava a relação entre múltiplas localizações, múltiplos intervalos de tempo - justamente a multiplicidade simultânea que eu associava à noção de cosmopolitismo. Fui então surpreendido pela expressão "cosmopolitismo vernacular" de Homi Bhabha, assim como por sua reteorização na antropologia por Pnina Werbner e, particularmente, pela noção de "cosmopolitismo discrepante" de James Clifford. Ao encontrá-las, eu me perguntei como essas teorias poderiam relacionar a minha história de escutar e fazer soar [sounding] jazz com as formas de escutar e fazer soar [sounding] de Nii Noi e Nii Otoo, as quais são ao mesmo tempo próximas e diferentes.

Logo se colocou a questão de como textualizar esse tipo de conversa, que sobrepunha escuta e sounding. E isso me levou diretamente a Bakhtin: tratava-se de voz, polifonia e dialogismo. Assim, em vez de textualizar essa conversa em uma escrita analítica, decidi localizar essas camadas de escutas de histórias de escuta por meio de narrativas. Imediatamente eu pensei: "Está bem, intersubjetividade é intervocalidade; esse é o modo pelo qual darei forma textual à questão". Isso fez com que eu pensasse em relacionar a filosofia linguística de Bakthin e Voloshinov com o tipo de problema que Jim Clifford coloca em seu ensaio sobre "cosmopolitismo discrepante". O que significa imaginar que nem todos os 
cosmopolitas pertencem a uma elite? $\mathrm{O}$ que significa imaginar que diferentes formas de viajar, sejam forçadas, não forçadas ou desejadas, ou ainda viagens mentais e viagens por meio de tocadiscos ou rádios, em vez de uma viagem no sentido físico do termo, bem podem fazer parte da constituição cosmopolita? Passei, assim, a prestar atenção aos livros na biblioteca de Nii Noi. O que devo saber sobre seu diálogo com esses livros, essas ideias? Com o que devo me engajar em suas fitas cassetes e gravações em LP? Comecei então a pensar nas distâncias entre a viagem física, o conhecimento sobre o mundo e o tipo de viagem que se faz ao escutar gravações e tocar junto com elas ou tocar junto com as pessoas que fazem esse tipo de música.

Eu me desloquei do som para o texto por meio da voz. Nesse processo, vime consultando Clifford, Werbner, Bhabha e Appiah para pensar como encontrar minha própria voz nesse tipo de mixagem. O livro Cosmopolitanism de Kwame Anthony Appiah foi muito, muito importante para mim, não apenas no contexto de Gana, mas também de uma perspectiva teórica e filosófica mais ampla em sua forma de pensar o cosmopolitismo como possibilidade de compatibilizar universalismo e diferença. Ele toca em questões como: o que significa ser enraizado e cosmopolita? O que significa ser patriota e cosmopolita? O que significa ser nacionalista e cosmopolita?

Passei assim a prestar muita atenção às vozes faladas e musicadas de Nii Noi e Nii Otoo. Antes mesmo de me sentir confortável para escrever sobre a intersubjetividade como intervocalidade, Nii Noi e Nii Otoo me disseram que queriam que eu produzisse uma gravação sua, queriam ter seu trabalho documentado e ser bem pagos para isso. Percebi então que filmar e gravar o som seria a melhor forma de iniciar nossa conversa. Assim, tanto a subjetividade quanto a intersubjetividade deslocaramse, de forma bastante literal, por meio da progressão do som para a imagem e depois para o texto, em termos de uma sequência de movimentos representacionais.

Tenho uma memória auditiva muito boa, mas não queria parecer um espião. Por isso perguntei a Nii Noi e Ni Otoo se eles se sentiriam confortáveis caso eu carregasse no bolso uma caneta que continha um gravador com um microfone. Esta me pareceu uma forma natural de tentar manter o som e a voz no primeiro plano da relação entre texto, textualização e contextualização. A este respeito, não posso deixar de enfatizar o quanto o exercício de pensar sobre a constituição subjetiva foi antes de tudo um exercício de pensar a relação entre intersubjetividade e intervocalidade.

Catarina Morawska: Steve, você parece estar descrevendo um processo colaborativo. Ontem discutimos essa reconfiguração da abordagem colaborativa no seu trabalho ao longo dos anos, bem como o seu comprometimento pessoal e político com múltiplos modos de saber e como o ato ou o processo de conhecer algo novo por meio da intervocalidade pode estimular diferentes formas de imaginação. Você também disse que a colaboração está ligada a uma oportunidade de teorizar a intermidialidade que deixamos passar na antropologia. Poderia expandir essa ideia para os nossos leitores?

Steve: Esta é uma ótima forma de seguir com o diálogo, Catarina, pois está diretamente relacionada à constituição de sujeitos e à força da pergunta de Iracema. Na minha primeira colaboração com Nii Noi e Nii Otoo, eu os ouvi a partir do enquadramento de alguém que tinha muita experiência prática, 
formação e conhecimento sobre jazz. Enquanto os escutava, eu também dizia a mim mesmo: "Eu sei o que você está fazendo. Estou no groove contigo. Estou no momento". Esta é uma sensação que os músicos costumam ter, uma sensação muito poderosa de que você compartilha um conjunto de referências, uma história de escuta das mesmas coisas, ainda que as tenha escutado de maneiras muito diferentes, e se pode partir disso como base para criar uma espécie de intimidade. Para mim, a primeira fase dessa colaboração foi uma intimidade auditiva. Senti uma intimidade sônica com esses outros músicos em virtude da minha própria história de escutar e musicar. Também senti imediatamente que seríamos amigos e trabalharíamos juntos. Na verdade, tive a estranha sensação de que nos conhecíamos há muito tempo.

Então temos a intermidialidade, e isso refaz os passos que eu descrevi em minha resposta a Iracema. Pois, afinal, o que fazemos juntos ao produzir som? Nós escutamos juntos diferentes gravações. Falamos sobre elas. Fazemos música juntos. Produzimos instrumentos. Desenvolvemos uma conversa descontraída com os materiais a partir dos quais se faz música, os instrumentos. Falamos sobre surdinas, sobre as diferentes formas como o jazz trabalha o timbre e a sonoridade. Conversamos sobre temporalidade, sobre a relação entre o swing no jazz, a síncope, o fraseado fora dos tempos fortes. Mas qual é a relação disso com o rigor dos ciclos temporais no ritmo da África Ocidental? Como trabalhar com essa variedade de mídias e materiais de improvisação na conjuntura do espaço africano e não africano? O som tornouse nosso primeiro meio de conversa e colaboração, e isso me levou a perceber que eu poderia fazer gravações, trabalhar com Nii Noi e Nii Otoo na edição e produção dessas gravações. Passei a fazer o que um produtor faz: escuta, encontra os pontos fortes do material e ajuda a reconhecê-los; ajuda a transformar coisas sutis e cheias de nuances em algo legível para um outro grupo de ouvintes. Ao me tornar um engenheiro e produtor, encontrei uma forma de contribuir para amplificar, literalmente, a música de Nii Noi e Nii Otoo.

Há ainda a questão de como escrever sobre tudo isso. Eis onde a intervocalidade, a narrativa e a produção de imagens aparecem. Nós produzimos um CD por ano para documentar o trabalho e três longametragens que estavam disponíveis antes da publicação da monografia. O livro teorizou a colaboração como intermidialidade ao apresentar uma versão estendida das notas contidas nos encartes dos CDs e DVDs. Textualizar o livro tornou-se também um modo de recontextualizar o material sônico e visual que nós gravamos e as narrativas que o cercavam. A colaboração tornouse então intermidialidade. A conjunção entre mídia sônica, visual, sônico-visual e textual é também a conjunção entre intervocalidade, intermidialidade e intersubjetividade.

Foi assim que a colaboração se tornou fundamental para o projeto de pensar sobre subjetividade e constituição de sujeitos, assim como para apresentar o trabalho localmente. Os produtos da pesquisa foram disponibilizados primeiro em Gana, para um público ganense, quando as pessoas puderam assistir aos filmes e escutar os CDs. Som-textoimagem no nível da constituição de sujeitos e da colaboração são forjados como uma espécie de intermidialidade. O signo compósito da colaboração é esse espaço intermídia. As coisas não estão congeladas em um CD, em um 
parágrafo de um livro ou em um DVD. Há sempre algo entre [inter]; há sempre alguma interação [inter-play] entre esses sons, ações, palavras, sensações, ideias e a forma como eles são mediados, representados e circulados.

Evanthia Patsiaoura: Em Jazz Cosmopolitanism in Accra, em especial no começo do capítulo dois, em que Ghanaba ${ }^{6}$ chama os norte-americanos de racistas, o modo como as histórias e as narrativas foram concebidas é bastante político, ainda que não abertamente. Ele fala sobre como os Estados Unidos queriam que os africanos "tivessem uma tribo", "falassem uma língua tribal", "tocassem tambores tribais". Esta é, para mim, uma forma evocativa de falar sobre o colonialismo, em um sentido amplo, e foi nesse momento, Steve, que percebi que seu trabalho é muito político, e que seu formato narrativo é muito analítico. Quero aqui conectar esta observação à forma como você aborda politicamente a intermidialidade. Para você, poderia a intermidialidade ser política no que tange ao fazer etnográfico ou às formas narrativas de maneira geral? E como as grandes viradas em sua carreira entre diferentes lugares de pesquisa, no uso de diversas mídias e nas muitas possibilidades de colaboração com seus interlocutores - informam a sua construção epistemológica por meio da intermidialidade e da intervocalidade?

Steve: Não era novidade para mim ser uma pessoa branca no mundo da música negra. Eu compreendia a polêmica política da escrita sobre jazz nos Estados Unidos, que envolve acadêmicos, músicos e escritores brancos numa mixagem com vozes afro-americanas. Aprendi essa história a partir da interação constante com a música e os músicos afro-americanos na adolescência. Então sempre me preocupei com a questão da autoridade, da voz, da perspectiva e, particularmente, de falar ou escrever por cima da história de outras pessoas. Isto também fez com que eu estivesse bem atento para permitir que meus interlocutores conduzissem nossas conversas e as revisassem antes que eu pudesse retransmiti-las.

Aprendi rapidamente, por exemplo, a deixar que Ghanaba começasse a conversa de seu jeito, em sua voz. Desenvolvemos uma relação única porque pude fazer algo que ele realmente queria ao atender ao seu pedido para que produzíssemos o filme Hallelujah!. E só consegui entrevistá-lo para a segunda metade do filme depois de quinze meses de rodada a performance da primeira parte. Àquela altura ele já estava confortável comigo e apenas o deixei suingar. Às vezes eu sabia que ele estava sendo bem provocador, mas eu simplesmente o deixava. Queria que a política aparecesse na sua narrativa, pela sua voz. Era assim: aqui temos Ghanaba, o mais famoso ícone do jazz ganense cara a cara com um branco segurando um gravador. O que ele vai fazer?

Tenho prazer em dizer que Ghanaba leu, ou eu li para ele, tudo que está no livro; o mesmo aconteceu com Nii Noi, Nii Otoo e Nii Yemo. Isto foi extremamente importante, não apenas em termos de confiança e colaboração, mas também no que diz respeito à performance da intersubjetividade e da intervocalidade. Certamente eu busquei escrever o mínimo possível a partir de uma perspectiva histórica pensada de forma hierárquica, deixando que meus interlocutores introduzissem, sempre que possível, cada um dos temas e atitudes políticas presentes no texto. Isto inclui as notas de rodapé. Muitas delas relatam os comentários que eles fizeram depois de ler o livro.

Em termos de "grandes viradas", eu diria apenas brevemente, Evanthia, que eu 
não tive muitos assim chamados grandes insights ou ideias na minha vida. Eu sou apenas, acredito, muito obstinado na forma como persigo as ideias que tive. A Papua Nova Guiné dos anos 1970, 1980 e 1990 continua sendo a origem de tudo o que eu ainda faço: escutar histórias de escuta; a antropologia do som e a antropologia da voz como respostas críticas às limitações da etnomusicologia; a acustemologia como engajamento entre produção de conhecimento e coprodução. Tudo isso, somado à auditoria dialógica e à edição dialógica, foi o que fiz depois na Europa, no Japão e na África Ocidental. E ainda remete à mesma tentativa de realizar uma investigação localizada na conjunção entre a socialidade e a materialidade do som.

Certamente trabalhar em um lugar como a Papua Nova Guiné, na floresta tropical, não poderia ser mais diferente do que andar pelas vilas no norte da Grécia ou conviver com pastores. Mas escutar cabras e ovelhas mostrou-se mais parecido com escutar pássaros na floresta do que eu jamais poderia ter imaginado. A África Ocidental e um espaço urbano como Acra com 6 milhões de pessoas - e a densidade e a complexidade linguística, histórica e cultural que isso implica talvez pareçam, superficialmente, uma "grande virada", mas as questões que imediatamente me atravessaram foram as mesmas. Mudar da música para o som e a escuta, fazer política, tornar a diferença audível por meio de um compromisso com a divulgação do meu trabalho igualmente em forma de texto, som e imagem é algo que fiz desde o começo.

Sound and Sentiment foi publicado depois do lançamento do primeiro LP da série de gravações do Institute of Papua New Guinea Studies. Foi uma contribuição política e pessoal à consolidação de um programa nacional de música.
Isso diz muito da minha relação com um país ao qual cheguei justamente no momento de sua independência. Realizei uma gravação, um livro e uma exposição fotográfica itinerante, tudo ao mesmo tempo. O interesse pela intermidialidade e por algumas dessas questões já existia. É claro que com o tempo as questões avançaram, sua teorização se desenvolveu e acredito que tenha um pouco mais de profundidade hoje do que tinha há 40 anos. Mas não penso muito nesse movimento como "grandes viradas", e sim como um aprofundamento de conversas e compromissos.

Suzel Reily: Gostaria de voltar a Nii Noi. Do que pude perceber de sua conferência e do filme a que assistimos ${ }^{7}$ havia certa marginalidade em sua posição em Gana porque ele parecia não seguir a orientação nacionalista que as pessoas esperavam de um músico. Isso fez com que eu me questionasse sobre o tipo de recepção que as gravações que você realizou tiveram em Gana, dada a posição marginal de Nii Noi decorrente de seu cosmopolitismo. Questioneime também como essa posição talvez contraste com o modo como essas mesmas gravações foram recebidas ou julgadas no "Ocidente", onde muitos ouvintes seriam capazes de perceber o que está acontecendo musicalmente ali por compartilharem, em certas dimensões, idiomas comuns. Eu me lembrei da ideia de inautenticidade estratégica [strategic inauthenticity] de Tim Taylor. ${ }^{8}$ Parece na verdade que o que temos aqui não é uma inautenticidade estratégica, mas algo que desconstrói esse conceito permeado por valores coloniais. De fato, Nii Noi e Nii Otoo se mantiveram totalmente autênticos quanto às suas próprias histórias de escuta. A questão é um tanto confusa, mas basicamente tem a ver com a forma como as gravações que 
vocês fizeram juntos foram recebidas em Gana e no Ocidente, e com o eventual contraste entre essas duas recepções. Ou ainda sobre até que ponto isto pode ter deslocado as fortes expectativas nacionalistas em relação aos músicos em Gana, ou ao menos ter dado a eles um maior espaço na mídia.

Steve: Esta é uma ótima questão porque me leva à indagação de Kwame Appiah: o que significa ser enraizado e cosmopolita? Eu reformulei a pergunta assim: o que significa fazer parte da vanguarda e ser ganense? O enraizamento de Nii Noi é muito potente em vários sentidos: ele estudou tanto a música ganense quanto os escritos pan-africanistas desde Kwame Nkrumah, Cheikh Anta Diop, Amílcar Cabral e Haile Selassie. Há, assim, uma ligação entre expansividade e enraizamento, mas alguns modos de expansividade podem levar à marginalização. Expandir para uma lógica do jazz diaspórico de vanguarda na época do movimento pelos direitos civis nos Estados Unidos pode soar progressista, mas não necessariamente significa conseguir tocar nos clubes de jazz em Acra, que esperam que se toque bebop e swing como se os músicos tivessem sido formados no Berklee College of Music, nos Estados Unidos. A expectativa local de um cosmopolita musical do jazz enfatiza a linguagem harmônica desenvolvida no jazz estadunidense, enquanto Nii Noi e Nii Otoo enfatizam mais a linguagem rítmica e a textura da percussão africana. Nii Noi não é marginal para o mundo da música africana, uma vez que fez gravações, filmagens e é retratado em um livro, hoje disponíveis em bibliotecas universitárias no mundo inteiro. Nossa colaboração produziu assim uma presença dele no cenário mundial, ainda que ele permaneça marginal em seu lugar de origem por não ser legível nem como um músico de jazz, nem como um músico tradicional ganense. Com Nii Otoo a história é diferente, já que ele vem da classe trabalhadora e é mais tradicional em muitos sentidos, musical e culturalmente. Hoje eu liguei para ele e disse: "vou falar com algumas pessoas sobre o nosso trabalho. Há algo que queira que eu conte a eles?". E ele respondeu: "Sim, diga a eles que acabo de receber o dinheiro dos royalties". Então me contou que o dinheiro veio em boa hora para pagar a cerimônia de seus filhos caçulas, que são gêmeos. Os royalties de livro, filmes e CDs são divididos entre todas as pessoas envolvidas. Essa afirmação de Nii Otoo demonstra seu orgulho de classe em ser bem remunerado pelo seu trabalho.

Rafael Cesar: Eu gostaria de perguntar algo relacionado a Jazz Cosmopolitanism in Accra. Liisa Malkki, em seu livro Improvising Theory, afirma que a etnografia faz parte de uma tradição de improvisação que é muito similar ao modo como a própria tradição do jazz incorporou a improvisação. Ao escrever o seu livro, você se inspirou em como músicos como Nii Noi e Nii Otoo lidam com a tradição e a transformação em seu ofício? Poderíamos ainda dizer que seu livro se relaciona à tradição antropológica assim como o trabalho deles se relaciona à cena do jazz contemporâneo?

Steve: Gosto muito do livro de Liisa, Improvising Theory, que li assim que foi lançado. É uma maneira admirável de representar um diálogo entre uma aluna e uma professora em campo. Acredito também que esta é uma grande contribuição para o método antropológico, ao esclarecer que muito do que fazemos em antropologia tem de ser constantemente inventado. Mas é melhor eu não começar a falar sobre invenção porque Iracema vai querer que fale sobre $A$ invenção da cultura, 
de Roy Wagner [risos], que é um tema importante em seu trabalho. A grande questão em relação à improvisação é que ela não costuma ser bem compreendida nos discursos ocidentais, tanto sobre música quanto sobre criatividade. Nesse sentido, acho que Improvising Theory desempenhou um papel importante ao romper com a ideia de método como um conjunto fixo de ferramentas empíricas para entender a pesquisa como um processo de diálogo e refinamento constantes. Isto me remete à linguística de campo. Vamos supor que eu e você não tenhamos uma língua em comum. Como faço para descobrir algo sobre sua língua? A melhor forma é fazendo você rir. Eu concateno algumas palavras aleatórias que ouvi em sua língua e faço você rir. Ao rir, o que você está me dizendo é que essa forma de combinar as palavras não está de acordo com a gramática. O mesmo ocorreu quando aprendi a compor canções em bosavi. Eu sobrepunha diferentes elementos sônicos e poéticos, e no momento em que as pessoas riam, eu sabia que estava errado. Na medida em que adquiri mais conhecimento, passei a cometer alguns erros de forma consciente para refinar minha percepção do que era certo ou errado, como um linguista de campo faria.

A improvisação precisa ser entendida dessa maneira, pois não significa simplesmente fazer qualquer coisa que se queira. A improvisação sempre se fundamenta em princípios, como a gramática para a linguagem e a poética para o canto. É preciso assim familiarizar-se com elementos sônicos, rítmicos, gramaticais, linguísticos ou poéticos para, a partir desse lugar, criar espaços onde se possa constantemente compor, recompor, inovar e inventar dentro das estruturas e de suas possibilidades. Acredito que pensar a improvisação como uma forma de tropo para a agência é bastante potente, assim como a improvisação pode ser pensada como um tropo para a subjetividade, para a habilidade de atingir plenamente nosso potencial e inventar constantemente.

Iracema: Isto se parece muito com a dialética entre invenção e convenção de Roy Wagner! [risos]

Steve: De fato. Essa é uma conversa que eu sempre tinha com Roy. Ainda que não tivesse muito conhecimento sobre jazz, Roy certamente incorporou essas referências à sua poesia. As referências musicais em seus livros são majoritariamente da Europa Ocidental. Curiosamente, ele admitiu ter desejo de compreender a constituição poética e musical no mundo daribi ou barok na Papua Nova Guiné. Como antropólogo, ele com certeza reconheceu que as formas musicais e sônicas de conhecimento são janelas poderosas para o que ele chamou de imaginação analógica dos papuásios. Maíra Vale: Ainda em seu livro, Jazz Cosmopolitanism in Accra, você nos conta como foi difícil achar uma voz narrativa que não performatizasse uma autoridade analítica. Narrativas, como você diz, não são de fato análises em termos acadêmicos, o que não significa que elas sejam não analíticas. Como você nos explicaria, então, esse movimento analítico que opera por meio de uma intervocalidade performativa mais do que de uma contextualização acadêmica? Gostaria que nos contasse um pouco mais sobre como produzir esse movimento no texto, de maneira a nos descrever como você compõe conhecimento por meio da narrativa e como isso pode se constituir como análise.

Steve: Vamos voltar a uma referência que Evanthia mencionou. Seria muito difícil explorar detalhadamente, no espaço de um capítulo ou um livro, temas como raça, colonialismo e a biografia de 
alguém como Guy Warren. Isto é muito complexo. Ao compor conhecimento por meio da narrativa, porém, pude reconstruir para os leitores como muito do que aprendi sobre a interação entre esses temas foi em conversas com Guy Warren. Dessa forma, minha voz analítica transparece na relação entre as minhas perguntas e as respostas dele. Ou seja, a narrativa performatiza o gesto analítico ao reconhecer como uma pergunta sempre conduz a algum lugar, embora resista à predeterminação da resposta. Essa foi uma maneira de criar espaços interativos, amigáveis e dialógicos que possuíam uma certa medida de inocência, o que me permitia ser surpreendido, ao mesmo tempo em que sempre esteve claro que as perguntas não eram ingênuas, nem pretendiam ter uma falsa ingenuidade.

O gesto ou o momento analítico que se realiza na narrativa leva a uma compreensão distinta da autoridade: a ideia de que a autoridade é gerida e emerge colaborativamente. Eu não estou tirando o corpo fora da análise, nem me recuso a citar teoria ou teóricos no livro. Tampouco estou evitando discussões intelectuais densas. Nii Noi faz leituras muito profundas e nós conversávamos sobre Fanon. Nossas conversas eram repletas de momentos analíticos que emergiam de muitas maneiras, surpreendentes e não surpreendentes, em virtude de seu vasto acervo de experiências, viagens e leituras.

Já outros tipos de gestos analíticos estão relacionados ao que afirmei sobre Nii Otoo. Eles eclodiam. Por exemplo, vocês se surpreenderam por ele não fazer a menor ideia de que Dave Brubeck era branco? Isto certamente é uma surpresa para a maioria das pessoas. E é claro que no momento da nossa conversa foi uma surpresa para mim. É também uma surpresa para muita gente que J.C. Abbey tenha feito uma marionete com quatro pernas para mostrar como James Brown dançava. Só depois eu o ouvi dizer: “Um ser humano não consegue fazer aquilo. Apenas quatro pernas conseguem". Essa relação entre o elemento de surpresa e o gesto analítico é muito importante. Ao ouvir Nii Otoo referir-se a Dave Brubeck como um "irmão", tive um flash: "ele nunca viu uma foto de Dave Brubeck!". Depois veio o reflexo analítico: "o que aconteceria se eu contasse a ele que Dave Brubeck é branco?". Por fim, a revelação analítica: Nii Otoo supunha que todos os programas de jazz transmitidos pelo Voice of America eram tocados por afroamericanos. Como ele poderia saber que o Voice of America, o meio que lhe permitiu conhecer o jazz quando criança, era um instrumento ideológico da propaganda norte-americana? O gesto analítico é assim performatizado e recentralizado por meio da colisão entre diferentes mundos provocada por esses pequenos momentos. Interessame perceber que, quando compomos conhecimento pela narrativa, o momento analítico pode tanto demorar a emergir quanto, por vezes, simplesmente acertálo em cheio.

Para enquadrar esse jogo entre narrativa e análise, propus um paralelismo entre os títulos dos capítulos do livro de modo a provocar um desvio. "De X a Y via Z": tudo surge por meio de alguma outra coisa. Cada título foi uma maneira de analiticamente dar voz ao modo como o conhecimento é revelado, de maneiras surpreendentemente diretas e indiretas. Nesse movimento, é a narrativa que faz o trabalho do desvio, como no título do capítulo de Nii Noi: "Do pan-africanismo aos afrifones via John Coltrane".

Catarina: Quero insistir nessa questão da teoria porque se costuma supor que a análise, assim como o texto analítico, necessariamente apresenta a teoria de 
forma explícita. Apesar de saber que esta é uma visão comum, em sua narrativa a teoria não aparece de maneira explícita, mas sim performatizada. Você não precisa citar Bakhtin, pois performatiza sua teoria na relação dialógica que tem com seus interlocutores. Isto tem um efeito estético muito particular. Sua análise parece ser feita, necessariamente, com um efeito estético ou como um efeito estético - eu não sei, isso faz parte da pergunta. Você diria que se fosse performatizar diferentes tipos de teoria ou mesmo as teorias de seus interlocutores, quaisquer que sejam, cada uma delas implicaria um efeito estético particular?

Steve: Antes de mais nada, acho que a ideia de "chegar ao ponto" sempre tem um efeito estético. Não é incrível ler um livro de suspense de trezentas páginas para tudo se resolver nas últimas cinco ou dez páginas? Pense em Agatha Christie. É somente no momento certo que cada descrição, cada desenvolvimento minucioso no enredo, aquela profusão de personalidades e tudo o mais que você leu vêm à tona. O mesmo acontece nos filmes de Alfred Hitchcock. O gesto analítico e o efeito analítico são igual e densamente estéticos para mim; eles operam em todas as mídias e de múltiplas maneiras. A palavra "pesquisa" é associada a um certo empirismo e a uma ideia de prestígio, mas como ousamos falar que artistas não fazem pesquisa? Como podemos dizer que as elaborações variadas, os desenvolvimentos, os refinamentos e os trabalhos em diferentes meios não são pesquisa? É uma pesquisa com os diversos materiais do processo e da produção. Para mim, estética e pesquisa, ou o efeito estético e o efeito da pesquisa, são revelados ao mesmo tempo e, às vezes, em uma espécie de flash.

Isto se conecta à improvisação, porque ela frequentemente está relacionada às maneiras de se chegar à nota certa, mover de um gesto a outro, fazer com que elementos se reúnam de forma cumulativa. Você escuta algo que está se desenvolvendo e pensa: "Aha! É aqui que tudo se encontra". Na música usamos a palavra "resolução". Na linguagem artística e perceptiva da Gestalt, falamos em "figura e fundo". Não importa como o chame, para mim isso é a textualização da análise na e pela narrativa. É uma maneira de tentar revelar o que poderia estar escondido; revelar sem sobredeterminar a revelação; conectar a revelação a uma forma de ressonância. Alguém tem de fazer o trabalho de reunir tudo isso. Quando se trata de improvisação, artistas e antropólogos são os primeiros expectadores. Não é justamente isso que Roy Wagner afirma sobre a invenção?

A teoria está muito mais próxima da química do que da arquitetura. É preciso deixar os elementos interagirem entre si e observar onde as interações se dão. A química também tem um efeito estético, e o mesmo ocorre com tudo o que me interessou na ciência. Como estudante de física, ao jogar uma bola de pinguepongue em uma tigela de água, eu media refrações e caminhos, entendia a relação entre ondas fisicamente visíveis e não visíveis, e como o espectro opera de forma similar em termos de acústica, cores e calor. A interrelação dos sentidos é a interrelação das artes. Todo o nosso aparato sensorial está profundamente sintonizado com espectros, bem como o material que produzimos a partir dele. É célebre a frase de Clifford Geertz: "a arte e os instrumentos para entendê-la são feitos na mesma fábrica". Esta é uma outra forma de dizer que a ressonância perceptiva, o aparato sensorial, está conectado à forma estética de sua construção. 
Iracema: Já que está falando sobre linguagem e materialidade, gostaria de fazer uma pergunta sobre o significante e seu dicionário com Bambi Schieffelin. ${ }^{9}$ Queria saber sobre a relação entre linguagem e som, especialmente no que diz respeito ao significante, à homofonia e à significação. Como você sabe, estou interessada em engajamentos pósestruturalistas com as possibilidades de transformação que residem na relação instável entre significante e significado, ou seja, em como a significação é reencenada ou transformada à medida que os significantes são iterados. Uma vez que você compilou com Bambi um dicionário bosavi-inglês-tok pisin - e dicionários são feitos de significantes - , o que você poderia nos dizer sobre a dimensão acústica do significante em relação à significação e à materialidade? Eu também teria curiosidade em saber um pouco mais sobre o processo de produção de um dicionário.

Steve: Sim, considero a produção de um dicionário uma atividade antropológica muito radical e poderia citar diversas razões para isso. A primeira delas, no caso bosavi, é o fato de ser algo profundamente político, embora não de forma explícita e barulhenta, quer dizer, o dicionário seria um instrumento que serviria a propósitos decoloniais na comunidade conforme as pessoas aprendessem a ler e a se engajar mais com o inglês e o tok pisin, a língua franca nacional [na Papua Nova Guiné]. Outra razão é que um dicionário, diferente da gramática, é acessível a qualquer pessoa. Não é preciso ser um linguista para usá-lo. Um dicionário lhe dá o prazer de achar algo e a surpresa do que não se pode encontrar. Há dois dias, amigos em Bosavi me mandaram uma foto de uma cobra que eu nunca tinha visto. Eu perguntei o nome e quando encaminhei a mensagem a Bambi, ela respondeu: "Oh!
Não está no dicionário!" [risos].

A produção de um dicionário é radical também porque se trata de um projeto colaborativo. Bambi e eu trabalhamos por quinze anos com cinco pessoas de Bosavi, alfabetizadas e não alfabetizadas, homens e mulheres, jovens e idosas. Isso foi fantástico! Além disso, o dicionário criou um forte vínculo com a comunidade, muito mais do que nossas monografias e artigos. A festa que os Bosavi prepararam quando o dicionário foi publicado honrou tanto as formas locais de conhecimento quanto as relações que fizeram esse conhecimento emergir.

Outro aspecto da radicalidade de um dicionário relaciona-se ao significado que a ele se confere localmente. Os Bosavi abraçaram-no como um signo de sua própria importância. Quando os políticos iam visitá-los, o que as pessoas em Bosavi queriam dar de presente, além das habituais penas e bolsas de malha? Uma cópia do dicionário! Era uma forma de dizer: "Temos uma língua e esses brancos levaram quinze anos para escrevê-la. E ainda foi publicada por uma universidade na Austrália" [risos].

As pessoas também moldaram o dicionário como um documento ideológico. Explicamos aos nossos colaboradores que em alguns dicionários havia uma certa divisão: na primeira metade se fazia o movimento de ir de uma língua para a outra e na segunda, se voltava a partir dessa última língua. Então eles disseram: "Não, não precisamos disso. Queremos ir da nossa língua ao inglês e ao tok pisin; vocês podem acrescentar uma pequena parte que vá do inglês para algumas palavras básicas em nossa língua". Eles estavam focados em si como os principais usuários do dicionário. Nós também explicamos que dicionários podem ter uma parte ao final explicando alguns pontos importantes de seu vocabulário. As pessoas responderam: 
"Bem, queremos todos os nomes para as diferentes partes da casa", ou "Queremos todas as formas de nomear relações". A construção dos apêndices foi um exercício fantástico para pensar sobre ideologia e representação linguística.

Isto resultou em um apêndice verdadeiramente único focado nas gənっ to, ou palavras sonoras. Isso porque na língua bosavi todas as vogais podem indicar algo sobre o espaço, pois essa língua utiliza em seu domínio poético uma grande quantidade do que poderíamos chamar, grosso modo, de termos onomatopaicos, mas que não se limitam a eles. São termos fonestéticos, no sentido dado ao termo por Roman Jakobson, ou seja, eles operam com enormes quantidades de informação sensorial. Estas podem estar relacionadas à altura e à profundidade, à proximidade e distância, a qualquer dimensão de espaço, tempo, volume ou densidade. E a fonestesia não faz apenas referência aos sons; esses termos podem referir-se à luz, ao deslocamento, ao movimento. Gugugəgə é um exemplo que gosto de dar porque mostra a relação entre precisão gramatical e processo de pensamento. Temos aqui uma consoante que aparece quatro vezes e duas vogais que aparecem duas vezes cada. A primeira é $u$, a vogal mais alta na parte posterior da boca. No paradigma fonestético, $u$ indica os sons que se movem de cima para baixo. A outra é , que é o som mais baixo na parte posterior da boca, o que indica que os sons se movem do mais próximo ao mais distante, ou seja, o movimento do som é para fora. Depois temos uma reduplicação: gu não é apenas gu, é $g u-g u$, ou seja, é reduplicado. Trata-se de um icônico clássico: pronuncia-se a consoante seguida da vogal duas vezes, e isto significa que o som é contínuo. A iconicidade é direta. Assim, gu é um movimento sonoro descendente e gugu é um som que se move para baixo contínua e repetidamente. Go é um movimento sonoro para fora e gogっ é um som que se move para fora contínua e repetidamente. Qual é o som que se move para baixo e para fora de forma contínua e repetida? O eco.

Suzel: Eu ia dizer cachoeira! [risos]

Steve: Por que o eco? Porque na profundidade e altura das camadas de uma floresta tropical, onde não se consegue enxergar mais do que um metro à sua frente, o que se entende como reverberação é uma continuidade do som que se move para baixo e para fora. É isso que cria o que chamaríamos de eco. Este é um exemplo clássico de como a iconicidade e a fonestética produzem algo que é simultaneamente uma imagem mental muito precisa e evocativa, poética e estética. De fato, é como a cachoeira em uma floresta tropical: ela se move continuamente para baixo ao mesmo tempo em que a água se move para fora.

No contexto da música, como sugeriu Suzel, um cantor poderia usar esse termo ao se referir a uma cachoeira que está para além do alcance da frase imediata que se canta e reforçar a relação fonestética e icônica com a canção como uma relação de movimento através de lugares, um caminho feito de nomes de lugares. Assim, o som pode fazer parte da maneira pela qual metalinguagens são formadas, dimensões extremamente precisas da linguagem são articuladas e, ao mesmo tempo, fazer parte do nebuloso, do efêmero, do ambíguo e da imaginação. Não é este, afinal, o recurso mais fantástico para um poeta? Poder usar uma palavra em uma língua que possa ter tamanha ressonância, ambiguidade e um jogo constante entre sua precisão e sua evaporação ou efemeridade? Que recurso incrível para um poeta! Os poetas carregam o mundo na boca. 
Iracema: Este é um ótimo exemplo de como a distinção entre concretude e abstração pode não fazer sentido. Da mesma forma que discutimos em relação à teoria e à narrativa.

Steve: Isso também retoma a pergunta de Catarina porque é um exemplo de como a linguagem pode simultaneamente ter o efeito de estética (poesis) e análise (precisão), quer dizer, como apreender gugu-gəgっ sem escutar a floresta? É preciso pesquisar o que é confuso e ambíguo acerca do som para chegar a essa forma de entendimento espacial e temporal da reverberação e do eco. Mas, ao mesmo tempo, é extremamente estético, leva a uma captura imediata, produz prazer, convida a entrar e é memorável.

Esta é uma outra característica das sequências de som. Você não as esquece. Algumas palavras, mesmo quando são novidade, parecem sempre ter estado ali. Quando foi a primeira vez que vocês escutaram a palavra ping pong? Vocês não foram imediatamente atraídos por essa ideia de que o som de ping pong era como a sensação de um jogo que se precisa escutar? Todas as línguas têm esse recurso, mas o que difere consideravelmente é até que ponto ele é formalizado e até que ponto é utilizado para entrecruzar os domínios da poética, da estética e da precisão. Roman Jakobson disse isso belamente ao sugerir que toda a linguagem é um mar de iconicidades potencialmente consumíveis, no qual apenas algumas serão de fato realizadas. Podemos imaginar uma língua que opere assim, inteiramente baseada nesse tipo de engajamento sensorial com o mundo. Jakobson deu uma importante contribuição à linguagem e ao pensamento ao esclarecer o potencial da iconicidade para ser sistemática, ou mesmo paradigmática. Em vez de passivamente seguir o dictum de que a linguagem é composta por relações arbitrárias entre significante e significado, Jakobson afirma que todas as línguas apresentam tanto relações arbitrárias quanto motivadas, as quais podem inclusive alternar-se constantemente. Então, em relação à sua pergunta sobre a importância do som, penso ser aí que ele se encaixa no estudo e na representação de uma língua. Não como um sistema abstrato e arbitrário de representações fonêmicas e fonéticas, mas como um sistema que motiva tanto a relação entre sensação e conhecimento perceptivo do mundo quanto a capacidade de engajamento quase imediato, simultaneamente abstrato e sensorial com o mundo. Esta é uma forma de conhecimento que demanda atenção e a sua representação em um dicionário como um recurso singular para os falantes da língua em questão.

Suzel: Acho que minha pergunta segue na linha do que estava dizendo, especialmente pela oposição entre abstrato e icônico. Ela tem a ver com a ideia de fazer soar [sounding]. Fiquei curiosa em saber como você pensa o conceito de musicar [musicking] de Christopher Small, ${ }^{10}$ que usa de vez em quando. Você poderia também comentar qual considera ser o rendimento de uma distinção entre música e som ou entre musicar e fazer soar?

Steve: Esta é uma ótima questão, Suzel. Gosto muito do trabalho de Christopher Small e de sua contribuição à discussão sobre a necessidade tanto filosófica quanto prática de transformar a linguagem descritiva nos estudos de música para um enquadramento processual da orientação ao objeto, a peças, composições e entidades fixas do som. O termo musicar [musicking] avança muito nesse sentido. Passei a usar uma abordagem diferente nos anos 
1970 e 1980 a partir do meu trabalho em Bosavi. Para relembrar a história muito rapidamente, uma pessoa morreu na aldeia $\log$ o que cheguei. Tive a oportunidade de assistir a uma forma local de lamento cantado-textual, cultivada pelas mulheres bosavi como uma incrível forma artístico-poética. Levou muito tempo para que eu percebesse isso, pois acreditava que estava em Bosavi para estudar cantos. Mas essa foi a primeira expressão sônica que escutei e gravei um modo de expressão que era sônica e emocionalmente muito bem organizado, articulado, focado, processado de forma tão poderosa que envolvia não apenas canto, mas também lamento - um lamento melódico cantado-textual. De uma certa maneira, minha ênfase em uma antropologia do som e na noção de sounding teve início assim que ouvi aquilo. Percebi ali que o "objeto" da minha pesquisa não era o canto, nem a música ou o musicar. Era a construção emocional e social no e pelo som.

De um modo similar, seis meses depois, quando passei a entender a língua suficientemente para trabalhar com a poética dos cantos bosavi, meus professores me levaram para escutar pássaros na floresta. Ora, minha educação musical prévia não incluía o reconhecimento dos cantos de pássaros! Assim, percebi-me em uma espécie de novo conservatório de música com professores que insistiam em que eu entendesse os sons, os nomes e os comportamentos dos pássaros para que compreendesse as expressões poéticas a eles associadas, e como cada um desses sons se relaciona às formas melódicas usadas nas escalas particulares desses cantos. Encontramos aqui dois pontos de entrada bem distintos para o mundo que chamamos de música. O primeiro é a generificação estruturada do lamento, ou do pranto cantado-textual. O segundo é a maneira pela qual o material poético e melódico subjacente ao canto era percebido como uma conversa com os pássaros. Ficava assim cada vez mais difícil usar palavras como música ou musicar de forma etnograficamente precisa ou teoricamente razoável, ainda que o argumento de mais processo que produto, no sentido proposto por Chris Small, certamente fosse importante. Mas, no limite, eu estava tentando descrever um modo de conhecimento que é ao mesmo tempo cosmológico e ecológico. Estava também tentando descrever um conjunto de relações baseadas no fazer soar e escutar que atravessa diversas espécies. Este foi um reconhecimento precoce do que hoje é chamado de etnografia multiespecífica. Mais importante ainda, em termos de uma antropologia da música, esse era um exemplo claro de como a produção de conhecimento indígena - neste caso, do som - descontrói categorias ocidentais, como a de "música". De fato, há forma melhor de desconstruir o termo "música" do que aterrissando em um lugar onde o lamento e os pássaros são simultaneamente fatos ecológicos e cosmológicos da vida, que estruturam entendimentos generificados acerca da relação entre emoção e som?

Quando uso a palavra sounding e falo sobre escutar histórias de escuta, sobre deslocar-se de uma antropologia da música e do som para a acustemologia e sobre o som como um sistema de produção de conhecimento, o que mais me fascina é a forma como o som, em Bosavi, conjuga os diferentes domínios da experiência, reunidos como uma máquina analógica de engajamento sensível com o mundo. Estudamos cosmologia e ecologia em departamentos distintos nas universidades e então nos deparamos com esse exemplo extraordinário de uma imaginação 
de conhecimento tão distinta, que, como têm mostrado outros estudos, existe também em muitos lugares na Papua Nova Guiné onde estive. O conhecimento do ambiente é em si uma representação e uma espécie de arquitetura do mundo dos espíritos. Cada uma dessas árvores e todos os seus frutos e aqueles que os compartilham; e porque os pássaros estão migrando em determinados períodos e fazendo certas coisas; tudo isso pode ser considerado um pedaço análogo do trabalho que Roy Wagner chamou de invenção. Como enfatizado diversas vezes por ele, a fonte criativa da imaginação humana é a parte mais importante da invenção. A criatividade deve ser central na discussão sobre agência, não algo secundário em relação a outros tipos de categorias fundantes. Se há uma categoria fundante na antropologia, concordo com Roy que é a criatividade, o que nos remete à discussão sobre improvisação. De qualquer modo e em qualquer lugar, a criatividade depende da improvisação. O que é improvisar, senão a produção de formas sutis e constantes de variação e repetição? Repetição com variação é exatamente como Jakobson definiu poética. Repetição com variação é o que Amiri Baraka chamou de "o mesmo que se modifica". É exatamente o que os jazzistas chamam de groove, em que toda vez há algo levemente diferente. Neste ponto, a Papua Nova Guiné tem um papel muito importante ao nos impelir a pensar sobre a criatividade da agência e a constante relação performativa entre escutar, fazer soar e musicar.

Rafael: Minha última pergunta é sobre o momento atual. Desde março de 2020 - a depender do país - vivenciamos uma crise sanitária sem precedentes causada pela pandemia do coronavírus, e assim continuamos. Para se adaptar a esse "novo normal", as pessoas voltaram-se cada vez mais para as mídias digitais para manter a comunicação apesar da distância. Contudo, muitos desafios têm surgido e boa parte deles tem a ver com o som. Enfrentamos dificuldades para nos entender, os ruídos de fundo causam interferências na comunicação, problemas relacionados à sincronicidade aparecem com frequência. Como poderíamos abordar estas questões a partir de uma perspectiva acustemológica?

Steve: Têm-se produzido muitos escritos e gravações sobre como o mundo nesses tempos de Covid está mais silencioso. Uns dias atrás, ouvi um programa de rádio em que Leah Barclay, uma importante ecóloga acústica australiana, falou sobre a importância dos projetos de gravação de som que ela e seus estudantes estão desenvolvendo agora na Austrália devido à quietude sem precedentes em diversos lugares cujas relações ecológicas eram antes muito mais dominadas pelas presenças humanas e tecnológicas. Acho tudo isso fascinante, mas resisto a relacionar nosso tempo-espaço a uma oposição binária entre barulho e silêncio. Para mim, a importância da escuta está sempre relacionada às alternâncias entre primeiro e segundo planos, sinais e ruídos, parcialidade e incompletude. Ora, o que estamos ouvindo durante esse período de isolamento social está mais relacionado aos sinais de uma simultânea conexão e desconexão entre nós. Não sei se há uma grande lição a ser tirada de tudo isso. Considero ser este um momento experimental. Nas montanhas, onde moro, vivencio a mesma quietude de sempre, nem mais nem menos aviões, pessoas, animais ou ventanias.

Como minha primeira experiência nesses últimos três dias de webinar via Zoom, diria apenas que a comunicação digital é mais cansativa. Ela nos demanda mais em alguns sentidos do que os modos de interação mais comuns. Eu me percebi 
muito cansado a cada noite depois de falar e normalmente não me canso facilmente em discussões e apresentações de pesquisas. Poderia sentar-me à mesa com vocês seis e falar por horas sem bocejar ao final. Nunca considerei esse tipo de interação acadêmica cansativa, mas neste momento sim. Acho que há um acréscimo de tensão nesse modo de comunicação. Em parte, porque nos perguntamos por quanto tempo ainda interagiremos dessa maneira e o quanto deveríamos estar reconhecendo que isso não é normal, e em parte porque estamos tentando ser eficientes e organizados de formas pouco usuais.

Tenho falado com muitos músicos que estão enfrentando essa nova realidade de usar a sala de casa como estúdio. Eles estão fazendo música em casa sem público, sem aplausos e sem pessoas assistindo. Para quem trabalha sozinho, esta não é uma grande questão. Mas para quem, como no jazz, depende da espontaneidade, das fagulhas, de ouvir e tocar no momento, tem sido um desafio devastador. É difícil saber como sentir que se está na presença do outro, em uma conversa de fato íntima. Formas de arte que dependem da espontaneidade e de uma espécie particular de atenção momentânea estão enfrentando muitas adversidades agora.

Tenho consciência do quanto este momento também reproduz e intensifica muitas das desigualdades que já existiam. Trabalho com Alex Coke, saxofonista e flautista de jazz, há muitos anos. Ele foi para Acra comigo e tocou com os músicos de lá por algum tempo. Nós dois temos todos os meios tecnológicos para fazer uma jam session virtual, mas é quase impossível estabelecer os meios tecnológicos para ensaiar e tocar com Nii Noi e Nii Otoo em Acra. A forma como a conexão de banda larga e os recursos para fazer esse tipo de interação são distribuídos ao redor do mundo não é a mesma. Então podemos ver os músicos da Jazz at Lincoln Center Orchestra, em Nova Iorque, tocando em sincronia de seu apartamento. Isto pode ser feito entre os Estados Unidos e a Europa sem o menor problema. Mas é muito difícil conectar Europa, Estados Unidos e Gana. Receio que esse momento apenas faça com que a desigualdade e seus efeitos se tornem mais barulhentos, mais altos, mais perturbadores e mais uma luta.

Maíra: Você nos falou que neste semestre irá lançar um DVD com algumas das suas palestras e conferências feitas por meio de uma mixagem entre textos, sons e imagens, assim como fez na conferência do nosso webinar. Gostaria de nos falar um pouco mais sobre esse projeto?

Steve: Tenho quatro conferências que desenvolvi para diferentes públicos ao longo dos últimos dez anos. Decidi que em resposta à sugestão de que as transformasse em um livro sobre acustemologia, iria gravá-las em DVD como performances faladas e acompanhadas por imagens, sons e apresentações de Power Point com muitos vídeos. Há uma palestra chamada "Acustemologia" que vai das minhas reflexões na floresta tropical em Papua Nova Guiné, passa pelo estudo dos sinos europeus em carnavais, igrejas, pequenas cidades e animais e chega até meu trabalho com buzinas de caminhão em Acra. Ela é guiada pela pergunta de como é possível conectar o ato de escutar aos sons desses diferentes lugares. Ao percorrer esta questão, traço os momentos empírico-teóricos que fundamentaram minha ideia de acustemologia.

A segunda palestra é sobre som, nostalgia e modernidade. Sobre o que aconteceu quando surgiram as bandas de guitarra em Bosavi, na Papua Nova Guiné. É uma narrativa acerca das diferenças 
entre os filhos e os netos das pessoas com as quais trabalhei em Bosavi nos anos 1970 e seus conhecimentos sobre o mundo. De como novas formas de poesia, percepção da floresta, preocupação com a memória e escuta dos pássaros foram fundamentais para a invenção de uma nova música. Durante algum tempo, fui uma espécie de parteira para o nascimento de um novo estilo musical na Papua Nova Guiné, mas estive também presente em uma espécie de funeral de parte da música mais antiga. Essa é uma oportunidade extraordinária para pensar sobre as invenções e as transformações acustêmicas.

A terceira é uma atualização do projeto sobre o cosmopolitismo do jazz em Acra, histórias que dão continuidade aos diálogos trazidos no livro. Mas dessa vez também o livro é parte da narrativa, e não apenas os sons que estávamos fazendo e escutando. Tento situar essa obra e o espaço dialógico que se abriu com ela em discussões mais amplas sobre o desenvolvimento de uma antropologia do cosmopolitismo e de acustemologias da intimidade diaspórica.

A quarta palestra conecta a acustemologia ao Antropoceno por meio da relação intersensorial das cigarras na Papua Nova Guiné, no Japão e na Grécia. Ela começa com a forma como as mulheres cantam com as cigarras na Papua Nova Guiné e como estas são associadas aos sinais de calor e mudança de temperatura no ambiente. A narrativa desloca-se daí para o meu engajamento com Hiroshima e minhas peregrinações ali no dia 6 de agosto para gravar e escutar cigarras, cujo som suponho ter sido o último que as pessoas escutaram antes de perecerem na atrocidade atômica. Finalmente, a narrativa se volta para a mais famosa referência literária às cigarras no Ocidente: o diálogo entre Fedro e Socrátes acompanhado pelo som das cigarras nos arredores da cidade antiga. Fui a lugares como Ilissos, em Atenas, e sentei-me sob os plátanos para gravar e filmar. Depois justapus essas gravações aos sons das notícias da televisão grega sobre a onda de calor. Essa conferência combina reflexões sobre o Antropoceno, calor e mudança climática em três diferentes lugares. As quatro palestras buscam, assim, evocar sensorialmente uma vasta extensão ao percorrer meus múltiplos projetos e apreciar uma variedade de produções de conhecimento no e pelo som. Espero lançar o DVD em novembro.

Iracema: Está bem próximo. Estou curiosa para assistir. Minha última pergunta tem a ver com a algo que você mencionou ao discutirmos o documentário J.C. Abbey: Ghana's Puppeteer [J.C. Abbey: marionetista de Gana]. Nele, a música e o teatro de marionetes emergem como lugares em que política e prazer podem convergir. Durante o nosso evento, você falou da marionete como essa figura ambígua capaz de desafiar politicamente o status quo. ${ }^{11}$ Ontem estávamos conversando mais informalmente sobre política e como tem sido difícil o momento em que vivemos. Você poderia falar um pouco sobre a relação entre música, prazer e política?

Steve: Em primeiro lugar, gostaria de dizer que está cada vez mais claro para mim que não é possível fazer nada sem prazer. Estamos sedentos por prazer estético, interpessoal, intelectual, físico. O termo "fome" abarca necessidades tanto físicas quanto mentais de florescer e continuar. Tal desejo resiste à depressão, à sobrecarga e ao fato de estarmos sendo pressionados por acontecimentos horríveis. Essa fome de que falo também está relacionada à resistência em sermos consumidos pela raiva.

Vejo-me enfrentando isso constantemente 
nas conversas que tenho com as pessoas. Começamos um diálogo e, quando percebo, já estamos falando alto, apaixonadamente e, em instantes, estamos com muita raiva. Soando como se voltássemos a ser crianças num estacionamento ou na escola, querendo atirar coisas para aliviar a exasperação que sentimos por viver em um sistema tão destrutivo. As pessoas que tomaram o poder têm tornado miseráveis cada vez mais vidas, como se sentissem prazer em fazê-lo. É essa crueldade que dificulta evitar a raiva neste momento. O que podemos fazer com a nossa fome? Acho que a ética do cuidado, nos termos de Foucault, não poderia ser mais fundamental. O que fizemos ao longo dos últimos três ou quatro dias é um modo de cuidarmos uns dos outros, não é mesmo? É um jeito de dizermos: "Nós estamos aqui. Ideias são importantes para nós. Iremos compartilhá-las e nutri-las. Ninguém irá tirar isso de nós". Vamos insistir no prazer de poder rir, beber ao fim do dia e falar sobre o que importa para nós. Esta é uma forma de dizer que não seremos reduzidos pelas forças aterradoras ao nosso redor a nada menos que plenamente humanos. Para mim, assim, o prazer, o engajamento com a estética e todas as suas ramificações políticas são cada vez mais necessários. Isso remonta ao que me atraiu na antropologia quando jovem. Tenho formação como músico e artista visual. Fui para a universidade e estava interessado em física, pois pensava que poderia trabalhar com acústica ou fazer acústica arquitetônica. Meu pai foi um músico que se tornou construtor, e eu tinha muito interesse nesse lado da construção e arquitetura das coisas, em como isso parecia com música, matemática e aquilo que me era familiar. Então, no meu primeiro ano de graduação, em abril de 1968, organizamos um debate sobre a guerra no Vietnã. No meio do evento uma pessoa entrou na sala e anunciou que Martin Luther King havia sido assassinado. Nesse momento um antropólogo se levantou e fez um discurso sobre as conexões entre militarismo e racismo. Fiquei completamente deslumbrado. Ele estabeleceu conexões entre a Segunda Guerra Mundial, a Guerra da Coreia e a Guerra do Vietnã, explicando como os governos desumanizam as pessoas para eliminar o debate e qualquer questionamento sobre a possibilidade de matá-las. Em seguida, dois outros antropólogos também falaram sobre raça, direitos civis, justiça social e militarismo. Eu chorei de emoção, fascinado. No semestre seguinte, em vez de cursar as duas disciplinas de matemática que estavam previstas, escolhi "Introdução à antropologia social" e "Introdução à antropologia biológica". Isso foi no segundo semestre de 1968. Desde então, nunca deixei a antropologia.

Essa é uma parte muito significativa da minha própria história, que me faz sentir uma conexão direta entre a antropologia que produzi e um comprometimento com as políticas antirracistas, anticolonialistas e antiguerra. Ainda assim, sempre me recusei a fazer antropologia às marteladas. Não estou interessado em escrever teoria ou etnografia de maneira barulhenta, nem em fazer pesquisa com fúria. Acho que tenho muito mais a oferecer dando a ver o poder político da criatividade e da agência. Por exemplo, na conclusão ao livro Jazz Cosmopolitanism enfatizo a importância da solidariedade na diferença. Ainda acho que isso é o que há de mais político na minha relação com Nii Noi e Nii Otoo, os melanésios, as pessoas no Japão, na Europa e em todos os lugares em que trabalhei. A colaboração realiza a política da solidariedade. Estou muito mais 
interessado na sutileza e nas nuances disso do que em jogar pedras. Fazer um filme como J.C. Abbey, Ghana's Puppeteer foi um modo de deixar que as pessoas retomassem a história colonial e a política pós-colonial por meio de seu engajamento com esses momentos e através de sua agência criativa. E sua agência criativa, ainda que em tempos politicamente complicados, é inspiradora. É inspirador observar esse desejo de uma agência expansiva no mundo. É inspirador testemunhar como essa expansividade é fundamental para superarmos os horrores, para que possamos não viver a vida como vítimas pós-traumáticas dos Bolsonaros e Trumps do mundo.

Agradecemos a Catarina Morawska pelo cuidado na leitura da versão final da tradução desta entrevista, bem como por seus valiosos comentários.

Iracema Dulley

https://orcid.org/0000-0002-0791-5313

Evanthia Patsiaoura

https://orcid.org/0000-0002-1583-0977

Maíra Vale

https://orcid.org/0000-0001-5562-0352

Catarina Morawska

https://orcid.org/0000-0002-6407-7854

Rafael do Nascimento Cesar

https://orcid.org/0000-0003-4901-246X

Suzel Reily

https://orcid.org/0000-0002-3352-9379

Tradução: Maíra Vale

Revisão: Iracema Dulley 


\section{Notas}

1 O trabalho de tradução do artigo "On Post-Ethnomusicology Alternatives: Acoustemology" [Alternativas pós-etnomusicológicas: a acustemologia], feito por Rafael do Nascimento Cesar e revisado por Iracema Dulley, está em andamento e deve ser publicado em breve pela PROA - Revista de Antropologia e Arte.

2 Processo Fapesp No. 2017/06642-5.

3 Quando lhe perguntamos sobre as possibilidades de uma tradução para a palavra sounding, Feld afirmou: "Na acústica, as propriedades físicas do som são divididas em três: o ataque, fase inicial do som; o corpo [sustentação], quando o som atinge sua intensidade total; o decaimento, que é o declínio de sua amplitude [volume]. Esses três momentos juntos são referidos como o 'envelope' - adorável metáfora! - do som. Então sound-ing, em um sentido puramente físico, enfatiza o corpo e o declínio do som, a forma como ele procede para o envelopamento completo após o breve momento inicial de ataque. Esta é uma forma de mostrar que o som é processual, um desdobramento do espaço acústico [timbre, tom] no tempo. O ataque é sempre muito breve, mas o corpo e o declínio do som variam muito. São essas propriedades processuais - a revelação horizontal do som como tempo e seu aspecto de duração que são marcadas no inglês pelo radical -ing". Ao longo da entrevista, manteremos a palavra no original ou, quando fizer sentido, ela será traduzida como "fazer soar".

4 Nii Noi Nortey e Nii Otoo Annan são amigos e interlocutores de pesquisa em Acra. Sobre sua relação com Feld, seus sons e caminhos entrelaçados, ver o livro Jazz Cosmopolitanism in Accra.

5 Do original musicking practices. O primeiro termo será retomado mais à frente nesta entrevista e tem sido traduzido na literatura como "musicar": "Em diálogo com as contribuições clássicas da etnomusicologia, apostamos que a noção de 'musicar' - tradução adotada para o termo musicking, cunhado pelo etnomusicólogo e compositor Christopher Small (1927-2011) - propõe um horizonte analítico capaz de reorganizar focos e atenções nas práticas de análise, enriquecendo a maneira como são produzidas, pensadas e analisadas as práticas musicais contemporâneas" (Villela, Toni, Muniagurria \& Grunvald 2019:18).

6 Ghanaba, jazzista de renome internacional, é um dos principais interlocutores de Feld no livro Jazz Cosmopolitanism in Accra. Ghanaba (literalmente, "de Gana") é o nome que o músico Guy Warren, também conhecido como Kofi Ghanaba, autoatribuiu-se ao retornar ao seu país de origem, em protesto ao que considerava uma falta de compreensão acerca da música africana no mundo do jazz.

7 Steven Feld ministrou no dia 5 de agosto a palestra "Sounding Subjectivity: Acoustemology in Accra". No dia 4 de agosto, discutimos o documentário J.C. Abbey: Ghana's Puppeteer. 
8 A referência aqui é a Timothy D. Taylor, autor do livro Global Pop: World Music, World Markets, no qual o conceito de "inautenticidade estratégica" é proposto.

9 Bambi Schieffelin, antropóloga melanesista especializada em antropologia linguística, é professora na New York University. Steven Feld fez sua pesquisa de campo entre os Kaluli em Bosavi juntamente com o casal de antropólogos Bambi e Edward Schieffelin. Mantém desde então uma parceria de trabalho com Bambi Schieffelin e os Kaluli.

10 O conceito musicking, traduzido para o português como "musicar", foi cunhado por Christopher Small no livro Musicking: The Meanings of Performing and Listening.

11 Durante o seminário, Feld apresentou a ideia de que por meio do teatro de marionetes é possível fazer uma crítica política que desafie o status quo ao colocá-lo em xeque por meio do humor sem, contudo, confrontá-lo diretamente. 


\section{Referências bibliográficas}

APPIAH, Kwame Anthony. 2006. Cosmopolitanism: Ethics in a World of Strangers. Nova York: Norton.

BHABHA, Homi. 1996. "Unsatisfied: Notes on Vernacular Cosmopolitanism". In: L. García-Moreno \& P. C. Pfeiffer (orgs.), Text and Narration: cross-disciplinary essays on cultural and national identities. Columbia: Camden House Press. pp. 191-207.

BRITO, Érico de Souza. 2019. "Acustemologia - Steven Feld". In: Enciclopédia de Antropologia. São Paulo: Universidade de São Paulo, Departamento de Antropologia. Disponível em: http://ea.fflch.usp.br/conceito/acustemologia-steven-feld. Acesso em 09/10/2020.

CERWONKA, Allaine \& MALKKI, Liisa. 2008. Improvising Theory: Process and Temporality in Ethnographic Fieldwork. Chicago: University of Chicago Press.

FELD, Steven. 2017. "On Post-Ethnomusicology Alternatives: Acoustemology". In: Francesco Giannattasio \& Giovanni Guiriati (orgs.), Perspectives on a 21st Century Comparative Musicology: Ethnomusicology or Transcultural Musicology? Udine: Nota. pp. 82-98. 2012a [1982]. Sound and SentimeBirds, Weeping, Poetics, and Song in Kaluli Expression. Durham: Duke University Press. 2012b. Jazz cosmopolitanism in Accra: a memoir of five musical years in Ghana. Durham: Duke University Press.

GEERTZ, Clifford. 2013 [1983]. O saber local: novos ensaios em antropologia interpretativa. Petrópolis: Vozes.

JAKOBSON, Roman. 2010. Linguística e comunicação. 22. ed. São Paulo: Cultrix.

SMALL, Christopher. 1998. Musicking: The Meanings of Performing and Listening. Middletown: Wesleyan University Press.

TAYLOR, Timothy. 1997. Global Pop: World Music, World Markets. Nova York e Londres: Routledge.

VILLELA, Alice; TONI, Flávia Camargo; MUNIAGURRIA, Lorena Avellar de \& GRUNVALD, Vitor. 2019. "O musicar como trilha para a etnomusicologia". Revista do Instituto de Estudos Brasileiros, 73:17-26, ago.

WAGNER, Roy. 2010. A invenção da cultura. São Paulo: Cosac Naify.

WERBNER, Pnina. 2011. "Paradoxes of Postcolonial Vernacular Cosmopolitanism in South Asia and the Diaspora". In: M. Rovisco \& M. Nowicka (orgs.), The Ashgate Research Companion to Cosmopolitanism. Farnham: Ashgate. pp. 107-124. 